\title{
Assessing the changes in shopper numbers within the London congestion charge zone
}

Recerved 21 March 2005

\section{Sheelah Turner}

is a market analyst with Solihull-based FootFall Ltd, a provider of retail pedestrian traffic monitoring systems with installations in 23 countries worldwide. She has over eight years' experience as an analyst working in the UK and overseas, covering a wide range of industry sectors.

\begin{abstract}
The introduction of the Greater London (Central Zone) Congestion Charging Scheme in February 2003 aimed to reduce the traffic congestion within central London and encourage a greater use of public transport. Two years on, the scheme is successfully achieving this aim. But some retailers located within central London have experienced noticeable drops in sales over this period. This paper analyses the changes in shopper numbers within the congestion charge zone, in comparison with shopper trends in London and the rest of the UK, and addresses some other contributing factors that have also impacted on people's shopping behaviour. Analysis has shown that while shopping numbers have declined within the congestion charge zone, weekday patterns differ from weekend patterns, with discretionary shopping trips on weekends facing a larger impact than shopping on weekdays. Furthermore, international events - the Iraq war and SARS - as well as major local transport issues cannot be disregarded in their impact on shopper behaviour.
\end{abstract}

\section{Keywords:}

London congestion charge, footfall, shopping numbers, pedestrian counting, retail impact

\section{INTRODUCTION}

'The worst traffic congestion occurs in central London. Businesses, bus passengers, pedestrians, residents, taxis, cyclists and all road users suffer as a result. Radical measures are needed. Alongside improving public transport, the Strategy adopts the principle of a congestion charging scheme in a zone of central London. Congestion charging provides a powerful and effective means of dealing with congestion on roads within and leading to the charging zone."

On Monday 17 February 2003 London joined the ranks of Singapore, Trondheim (Norway) and Durham as the Greater 
Role of retail in Central London

Impacts on John Lewis
London (Central Zone) Congestion Charging Scheme was introduced. As it stands, London is still the only major city in the UK that has designated a central area as a restricted zone for traffic $^{2}$ and levied a charge on those entering the area during specified times on weekdays.

\section{Aim of congestion charging}

The congestion charge is payable by drivers of all motorised vehicles (except those with exemptions as granted by Transport for London) entering the central London area between the hours of $7 \mathrm{am}$ and $6.30 \mathrm{pm}$ Monday to Friday, excluding public holidays.

According to Transport for London (TfL):

\section{'Congestion charging is a way of ensuring that those using valuable and congested road space make a financial contribution. It encourages the use of other modes of transport and is also intended to ensure that, for those who have to use the roads, journey times are quicker and more reliable. ${ }^{3}$}

The charge, according to TfL, is to make drivers think twice about using their car and to consider alternative forms of transport if they want to journey into central London. As such, the aim of the congestion charge is to reduce traffic congestion within central London and encourage greater use of public transport, which in turn is to receive funding through the money raised by the charge.

\section{Broader reported impacts}

The retail economy within the congestion charge zone is enormous. The Oxford Street/Regent Street/Bond Street triangle is one of Western Europe's premier retail locations. As at June 2003, there were estimated to be more than 357,000 retail employees in London, equating to 13 per cent of total employment in London, ${ }^{4}$ and the retail economy was in excess of $£ 15 \mathrm{bn}$. It is estimated that Oxford Street itself accounts for more than $£ 5$ bn of this amount. Consequently, after the introduction of the congestion charge, retailers and landlords were likely to pay particular attention to any effect or perceived effect on retail performance.

In one of the most recent surveys, in early 2005, the Royal Institute of Chartered Surveyors reported that nine out of ten retailers within the zone view the introduction of the congestion charge as having an adverse effect on business. ${ }^{5}$ John Lewis has been by far the most vocal of retailers in commenting on a change in sales performance after the introduction of the congestion charge. Two econometric models produced for John Lewis ${ }^{6}$ by Imperial College London, led by Professor Michael Bell, both show significant falls in sales since the introduction of the congestion charge.

- A 5.5 per cent drop in sales over the period analysed at the Oxford Street store alone; extrapolated to the entire Oxford 
Transport for London comment
Street economy this would mean over $£ 300$ m being lost from retail sales.

- When factoring in the relationship between all six John Lewis London stores and taking into account the rapid growth of Bluewater, estimates indicate that the drop in sales at the Oxford Street store attributable to the congestion charge is 8.21 per cent.

Further findings from this study were that over 8 per cent of John Lewis customers have changed their shopping habits as a result of the charge, and the 'vast majority' of those now shop less frequently at the store. Those shopping less frequently at John Lewis Oxford Street are also shopping less frequently in the Oxford Street area itself - indicating that the reduction in sales at John Lewis Oxford Street is not an issue specific to John Lewis.

Sir Stuart Hampson, chairman of the John Lewis Partnership, indicated that the "question as to whether the charge has had an impact on retailers is now beyond dispute and cannot be dismissed. We do not believe it is prudent to embark on extending the zone, or to introduce similarly blunt schemes to other cities in the face of today's evidence, without further study. ${ }^{7}$ The report concludes that, since the introduction of congestion charging, "customers are coming less to John Lewis Oxford Street and the Oxford Street area as a whole. It is not the case that John Lewis customers have simply diverted to other stores in the area. ${ }^{8}$

TfL has reported on several occasions that the decline in retail sales pre-dated the congestion charge and that central London shops were now outperforming the rest of the UK. Its own research found twice as many retailers attributed the fall in sales to the general economic downturn as to the congestion charge, and overall the impact of the charge on trade was said to be 'very low'.

Colliers CRE reported in June $2004^{10}$ that the average prime rent within Central London has remained static during the 12 months to May 2004, reflecting, at least in part, the effect of the congestion charge on retail sales. In contrast, within outer London prime rents have risen, on average, by 4.9 per cent, reflecting the different trading conditions inside and outside the congestion charge zone.

\section{BROAD OVERVIEW}

It is clear that the aim of the congestion charge zone in the overall context of the Mayor of London's Transport Strategy of 2001, plus the various revisions since, is to reduce traffic congestion in central London and as a result reduce the associated air and noise pollution. This in turn would have the effect of making the central area more desirable to both regular and overseas visitors and eventually would enhance the business environment of London, which is still regarded by many as a key business hub for the UK.

Yet there is still significant debate concerning the effect that restrictions on road transportation are having on the performance of the major retail centre that is central London. This paper thus 
Comparison of weekly shopping trends seeks to assess the impact of the congestion charge on the number of shoppers who are frequenting the retail stores within the congestion charge zone since the introduction of the charge, taking into account other key factors that could affect those changes.

\section{INDEX CREATION}

In order to analyse the trends in the number of shoppers within the congestion zone, an index of shopper trends has been created from shopper numbers in a representative number of individual retailers located within the congestion zone. These retailers cover a crosssection of the main key retail categories - clothing and footwear, health and beauty, music, sportswear.

The index allows analysis of changes in the number of shoppers over time, both on a weekly basis and broken down into weekdays and weekends.

For comparative purposes, this London Congestion Zone Index will be compared to an additional index that has been created for the remainder of the London region - the London Index. Lastly, a national index - the UK National Index - will be used as a benchmark of the shopping trends across the whole country.

\section{FIRST YEAR ASSESSMENT: FEBRUARY 2003 TO JANUARY 2004}

There is little doubt that the year February 2003 to January 2004 saw a drop in the number of shoppers in central London in comparison to the previous year (February 2002 to January 2003). In fact, this declining trend was not only evident in central London, but across London and the UK too, although to a lesser degree; this can be seen in Table 1 .

Comparing the trends in the weekly number of shoppers over the whole year, Table 1 shows that total weekly shopper numbers declined dramatically within the congestion charge zone - more than a 10 per cent decline year on year. Lesser declines in shopper numbers were evident in London (outside the congestion charge zone) as well as in the UK as a whole.

Since outer London suffered less of a decline, it appears that there may have been a diversion of shoppers from central London into the rest of London. It is, however, difficult to understand fully the behaviours of different types of people by looking at the weekly totals. While the weekdays are characterised by working people, weekends are also typically the shopping grounds of out-of-town

Table I: Change in weekly shopper numbers: February 2003-January 2004 versus February 2002January 2003

\begin{tabular}{ll}
\hline Region & Change in shopper numbers (\%) \\
\hline London congestion zone & -11.3 \\
Outer London & -0.2 \\
UK national & -0.8 \\
\hline
\end{tabular}




\section{Weekday shopper trends}

\section{Weekend shopper trends}

Table 2: Change in shopper numbers: February 2003-January 2004 versus February 2002-January 2003

\begin{tabular}{lcc}
\hline Time period & London congestion zone (\%) & Outer London (\%) \\
\hline Weekdays & -3.6 & +1.1 \\
Weekends & -12.5 & -3.2 \\
\hline
\end{tabular}

visitors and tourists. Thus, analysing the impacts on different days will allow a better understanding of the dynamics of the changes in shopper numbers.

Analysis of the trends in shopper numbers during the week (Monday to Friday) against weekend shopper numbers reveals an interesting anomaly (Table 2): shopper numbers over the weekends declined more significantly than during the weekdays.

The weekday shoppers are usually workers within central London, who continue to travel into the zone in order to work. TfL reported ${ }^{11}$ that total weekday traffic decreased from 2002 to 2003 (post-charging) by 14 per cent, with decreases in the number of cars of 33 per cent being partially offset by increases in the number of buses and coaches (up 23 per cent) and two-wheeled vehicles (up 15 per cent). The shift away from cars (to public transport and two-wheeled vehicles) has been much larger than the decline in shopper numbers, suggesting that the congestion charge has played only a small part in influencing shopper numbers.

Weekends in general have shown a decline in shopper numbers over the period measured. Outer London experienced a decline in the number of shoppers at the weekends of approximately 3 per cent. Central London seems to have suffered a more dramatic decline in shopper numbers, with a decline in excess of 10 per cent. In contrast to the weekdays, the discretionary shoppers who shop in central London at the weekends appear more sensitive to influencing factors, including the congestion charge. While there are numerous factors that have had an influence on shopper trends in general (discussed later), one factor could be particularly relevant to weekend shopping habits: clarity over weekend congestion charging.

While the marketing and information campaigns for the congestion charging have been primarily focused on the London area, many shoppers travelling into central London by car at the weekends come from further afield, to where information and marketing campaigns may not extend. Anecdotal evidence suggests that confusion over whether congestion charging applies at weekends may deter shoppers from venturing into London. Furthermore, if shoppers believe the charge is in force, confusion over how it is paid may add to the anxiety of a trip to London. In order to avoid the confusion, shoppers may be inclined to visit other shopping locations.

The introduction of the congestion charge was a single factor at 
Impact on passengers

Impact of increased media coverage play during a general period of upheaval during 2003. As such, it is necessary to identify other factors that affected consumer behaviour.

\section{SIGNIFICANT EVENTS DURING 2003}

\section{Central Line closure, 25 January 2003-12 April 2003}

An accident occurred on 25 January 2003 on the Central Line at Chancery Lane station when a motor fell off underneath a train and derailed several coaches. As a result, the Central Line was closed. While engineers were undertaking the necessary maintenance on the fleet of 85 trains, TfL ran a large network of emergency buses in order to cope with the additional passengers, and many people found their journeys to and from work taking twice as long as usual. The final stations on the Central Line were opened on 12 April 2003, after a period of 11 weeks.

The closure of the Central Line affected an estimated 600,000 passengers a day. While facing the increased commuting times, consumers were less likely to stop and browse and more focused on reaching their destination with as little inconvenience and delay as possible.

\section{Official Iraq war, 19 March 2003-1 May 2003}

The threat of weapons of mass destruction from Iraq prompted weapons inspections by UN weapons inspectors, starting in November 2002, as the USA prepared to tackle international terrorism. On 17 March 2003 President Bush gave Saddam Hussein a 48-hour ultimatum to leave Iraq or face war. Invasion of Iraq by US forces followed on 19 March 2003, and the war in Iraq started.

The official war was short-lived, and on 1 May 2003 the USA declared an end to major combat operations. But troops have remained in place for over two years since then as general unrest and skirmishes continued.

The war was faced with apprehension and uncertainty by people across the globe. The events of 11 September 2001 changed the nature of terrorism, and vulnerability was felt by many worldwide, especially those living in large cities. The collapse of the Twin Towers showed that terrorists would stop at nothing - and that anything was possible.

Due to the increased media coverage of the war, with live footage broadcast continuously through various media channels, the war became more a part of the lives of the general population in both the UK and the USA. Threats in Iraq were felt to exist at home too, and fear of a backlash attack from the Iraqis was uppermost in many people's minds. This general uncertainty and fear caused people to avoid busy locations (for fear of bombing) and also curtail their travelling (for fear of airplane terrorism). The impacts on tourism are discussed later. 


\section{Impact on travel patterns}

\section{SARS, 12 March 2003-2 July 2003}

After the emergence of a few cases of an atypical pneumonia from South Asia, on 12 March 2003 the World Health Organization (WHO) issued a global alert about a new infectious disease known as sudden acute respiratory syndrome (SARS). The disease was reported to be airborne and very infectious, and spread rapidly from South Asia to Canada. The WHO heightened the global health alert, and included rare travel advisories to international travellers.

These travel advisories reduced the general willingness of people to travel internationally - not only to those places affected by the outbreak, but to anywhere necessitating a long-haul flight.

As the disease was brought under control by authorities by midJune, the WHO started lifting travel advisories from cities and countries. On 2 July 2003 the final city was removed from the travel advisory listing.

During the period of the advisories - and for some time afterwards - many people avoided international travel, not only to the affected areas, but to many other destinations. The lack of full understanding of the nature of the disease - and the rapidity with which it surfaced and spread - resulted in an underlying fear of travel. The concern of possibly contracting the airborne disease from fellow passengers in the close confines of an aircraft cabin was sufficient to deter many travellers from most longer trips, in favour of short flights.

\section{Fall in tourism numbers due to terrorism fears and SARS}

With London being one of the top tourist destinations within the UK, tourism plays an important part in its economy. Government figures indicate that, during the first year of the congestion charge, the number of tourists from North America dropped by more than 5 per cent (see Table 3). Since North Americans tend to enjoy shopping as part of their tourist experience, the declining tourist numbers also impacted on shopper numbers.

Similar to the North American tourists, Western European tourists were avoiding their long-haul destinations of North America and Asia, and were more likely to select short-haul tourist destinations such as the UK. Although still cautious about travelling, there was an increase in the number of European tourist visits. Travellers from further afield were also displaying caution, with a very small increase in tourist visits.

Table 3: Year-on-year change in number of overseas visitors: February 2003-January 2004 versus February 2002-January 2003

\begin{tabular}{lc}
\hline Country of origin & Change in number of tourists (\%) \\
\hline North America & -5.1 \\
Western Europe & 3.2 \\
Other areas & 2.4 \\
\hline
\end{tabular}

Source: Office of National Statıstics ${ }^{12}$ 


\section{Comparison of weekly shopper trends}

\section{Comparison of weekday and weekend shopper trends}

Table 4: Change in weekly shopper numbers: February 2004-January 2005 versus February 2003January 2004

\begin{tabular}{ll}
\hline Region & Change in shopper numbers (\%) \\
\hline London congestion zone & -3.5 \\
Outer London & -3.9 \\
UK national & +1.3 \\
\hline
\end{tabular}

\section{SECOND-YEAR ASSESSMENT: FEBRUARY 2004 TO JANUARY 2005}

In the second full year after the introduction of the congestion charge, interesting trends were displayed. When comparing February 2004-January 2005 against February 2003-January 2004, there were conflicting reports from different regions. While the UK as a whole experienced an increase in the number of weekly shoppers (see Table 4), both outer London and the congestion charge zone were experiencing declining weekly shopper numbers.

It appears from Table 4 that the decline in shopper numbers evident within the congestion charge zone is less than the decline in shopper numbers in outer London. In other words, the cause of the declining shopper numbers in central London is not specific to the congestion charge zone, but has a wider impact on outer London too.

This comparison between the congestion charge zone and outer London is continued, with shoppers divided according to weekday or weekend shoppers (Table 5). The congestion charge zone has actually experienced a rise in the number of shoppers during the weekdays, with a continuing decline over the weekends. In comparison, outer London has seen a decline in shopper numbers on weekdays as well as over the weekends.

It appears that those in central London during the week have settled into a routine and are continuing their normal shopping patterns. Weekend shopper numbers continue to decline, however.

\section{SIGNIFICANT EVENTS DURING 2004}

\section{Madrid bombing, 11 March 2004}

11 March 2004 saw bomb attacks on four Madrid trains which killed 191 people and injured many others. Purportedly the work of Al Qaeda, most capital cities, including London, quickly went on high alert.

Table 5: Change in shopper numbers: February 2004-January 2003 versus February 2003-January 2004

\begin{tabular}{lll}
\hline Time period & Congestion charge zone (\%) & Outer London (\%) \\
\hline Weekdays & +0.4 & -2.8 \\
Weekends & -6.5 & -4.0
\end{tabular}


The tragedy did not affect shopper numbers in the same prolonged manner as the terrorist fears during the Iraq war in 2003. There was a fall in the zone of -1.3 per cent week on week, instead of the rise normally experienced at that time of year, but shopper figures the following week rebounded with a 3.9 per cent rise, outstripping the national trend at that time as habits returned to normal very quickly.

\section{Euro 2004, 12 June 2004-4 July 2004}

The European Football Championships (Euro 2004) saw UK retail experiencing a lift, with strong sales and footfall reflecting the positive impact of the tournament on consumer confidence. During the competition, the UK as a whole saw rises of 3.6 per cent and 1.8 per cent week on week respectively (from 14-27 June 2004). The congestion zone, however, saw a modest rise of 1.2 per cent and a fall of -0.2 per cent over the same period. This suggests that the area may be far less susceptible to the impact of partisan national events, perhaps due to the number of foreign visitors diluting the effect of the 'feel-good-factor shopping' experienced across the nation as a whole.

\section{Rise in tourism numbers}

2004 saw a revival in tourism. There was a marked increase in longhaul travel, especially from North America, and short hauls from Western Europe (Table 6). This was a result of people returning to the skies, feeling safe again after the uncertainty of the previous 12 months. Increased personal wealth in Eastern Europe, the budget airlines opening the UK up to this area and the Baltic States and an unrestricted Asia led to a dramatic 20 per cent rise in traveller numbers from other areas.

The extra opportunities for tourism contributed to the year-onyear increases in weekly shopper numbers, although it is uncertain that this significantly increased spending in the area as the weaker US dollar may have impacted on the spending power of the North Americans.

Impact of congestion charge on shopper numbers

\section{CONCLUSION}

This investigation into the changes in shopper numbers has revealed that there have been some declines in the number of people visiting

Table 6: Year-on-year change in number of overseas visitors: February 2004-December 2004* versus February 2003-December 2003

\begin{tabular}{ll}
\hline Country of origin & Change in number of tourists (\%) \\
\hline North America & 8.3 \\
Western Europe & 9.9 \\
Other areas & 20.9 \\
\hline
\end{tabular}

Source: Office of Natıonal Statıstics ${ }^{13}$

* Most recent data available 
First year impact

\section{Second year impact}

\section{Weekend and weekday shopper trends}

shopping locations within central London. But there appear to be other significant events that may have also contributed to the fall in numbers.

While there were strong declines in shopper numbers in central London in the first year after the introduction of the congestion charge, the year was also characterised by great international uncertainty (the Iraq war and the outbreak of SARS), as well as major local transport disruption. All of these factors impacted on the number of shoppers out and about in central London. What is more, the UK as a whole saw a decline in the number of shoppers, although not to the same extent as was experienced in central London.

The second year after the introduction of the charge saw further declines in shopper numbers in both central London and London as a whole, even though the UK overall experienced an increase. Fears of attacks on large cities were heightened after the bombing of trains in Madrid, possibly further impacting on shopping behaviour in large cities.

Important, however, is closer examination of the differences in trends on weekends and weekdays. While weekday visits into central London are typically more business driven, weekend shopping is more discretionary. Weekend shopper numbers have seen a large fall - probably as a result of people being unsure about whether a congestion charge is payable, and electing to shop elsewhere.

\section{References and Notes}

1 Mayor of London (2001) 'The Mayor of London's transport strategy Highlights', avallable at www.london.gov uk/mayor/strategies/transport/pdf/highlights2.pdf, accessed April 2005.

2. Durham's scheme is more limited and on a smaller scale than the one in London

3. Transport for London (2003) 'Congestion charging .. exemptions and discounts', available at www.cclondon.com/exemptions.shtml, accessed April 2005.

4. London Retall Consortium (2003) 'Statistics', avallable at www.brc.org.uk/lrc/ statistics.htm, accessed April 2005.

5. Royal Institute of Chartered Surveyors (2005) 'Congestıon charge hits retailers', available at www.rics.org/property/infrastructure/ congestion + charge + hits + retallers.htm, accesssed April 2005.

6. John Lewis Partnership (2004) 'Report on the impact of congestıon chargıng', avaılable at www.johnlewispartnership.co $u k /$ templatepage aspx? pagetype $=$ cat $\&$ pageid $=42$.

7. Ibid.

8. Ibid.

9. Transport for London (2004) Impacts Montoring - Second Annual Report Aprll 2004. available at www.tfl.gov.uk/tfl/cclondon/cc_monitoring-2nd-report shtml, accessed April 2005.

10 Colliers CRE (2004) 'In-town retail rental growth remains static in central London', avallable at www.colliers.com/markets/unitedkıngdom/news $/$ MSRR2004\%la $=$ en. accessed April 2005.

11. Transport for London, ref. 9 above.

12. Office of National Statistics 'Overseas travel and tourism', avalable at www.statistics.gov.uk.

13. Ibid. 